\title{
Membangun Kemandirian Pangan Melalui Manajemen Komunikasi Pemasaran Sate Bandeng Sebagai Produk Unggulan Kota Serang
}

\author{
Rahmi Winangsih, Nurprapti Wahyu Widyastuti, Yeni Widyastuti \\ Universitas Sultan Ageng Tirtayasa \\ Email: winangsih68@yahoo.co, nurprapti.wahyu@untirta.ac.id, yeni_arh@yahoo.co.id
}

\begin{abstract}
ABSTRAK
Kuliner sate bandeng memiliki potensi untuk dikembangkan sebagai komoditas pasar. Kuliner ini awalnya hanya dapat dikemas dalam bentuk kemasan dus yang hanya bertahan selama 2-3 hari saja. Namun saat ini, sate bandeng dapat dikemas untuk jangka waktu yang lebih lama, yakni 10 bulan dengan kemasan foil melalui proses penggunaan mesin vacum. Dengan adanya metode pengemasan ini, sate bandeng memiliki potensi yang lebih luas sebagai komoditas pasar sebagai oleh-oleh karena lebih tahan lama. Kota Serang dapat mengembangkan kuliner yang satu ini karena memiliki potensi pasar, daya jual beli, dan komoditas pasar lebih luas sebagai oleh-oleh. Pelaku UKM sate bandeng akan diberikan pengetahuan mengenai branding. Pengetahuan dan pendidikan mulai dari kemasan produk, sampai pada cara memasarkan produk, baik yang konvensional maupun yang online. Sesuai dengan perkembangan ilmu komunikasi pemasaran, saat ini media sosial, Media sosial mampu memberikan solusi bagi permasalahan tingginya biaya pemasaran Peningkatan kualitas dan kuantitas produk sate bandeng yang tetap terjaga, selain dapat dilakukan melalui berbagai pelatihan dan pendampingan, juga publikasi yang cukup untuk membantu perluasan pasar. Promosi seefisien mungkin, dengan biaya promosi yang tidak mahal namun mampu menyentuh pasar dengan jumlah yang tak terhingga banyaknya. Era sekarang cara ini sudah menjadi model komunikasi pemasaran yang banyak digunakan penguasaha, murah dan menguntungkan. Oleh karena itu, metode komunikasi pemasaran digital atau online perlu menjadi pendekatan yang dapat diaplikasikan oleh para pengusaha, dengan catatan tetap menjamin kualitas dan kuantitas produk, agar konsumen tidak kecewa.
\end{abstract}

Kata Kunci: branding, pemasaran online, sate bandeng

\begin{abstract}
The milkfish satay culinary has the potential to be developed as a market commodity. Initially, this culinary could only be packaged in the form of cardboard boxes which only lasted for 2-3 days. But this time, milkfish satay can be packaged for a longer period of time, which is 10 months with foil packaging through the process of using a vacuum machine. With this packaging method, satay milkfish has wider potential as a commodity market as a souvenir because it is more durable. The city of Serang can develop this culinary because it has market potential, buying power, and wider market commodities as souvenirs. The participants of UKM satay will be given knowledge about branding. Knowledge and education ranging from product packaging, to how to market products, both conventional and online. In accordance with the development of marketing communication science, currently social media, social media is able to provide solutions to the problem of high marketing costs. Increasing the quality and quantity of satay milkfish products that are maintained, in addition to being done through various training and assistance, as well as sufficient publications to help market expansion . Promotion as efficiently as possible, with inexpensive promotional costs but able to touch the market with an infinite amount. In this era, this method has become a marketing communication model that is widely used by businesses, cheap and profitable. Therefore, digital or online marketing communication methods need to be an approach that can be applied by
\end{abstract}


entrepreneurs, with a note that still guarantees the quality and quantity of products, so consumers are not disappointed.

Keywords: branding, online marketing:, satay milkfish

\section{PENDAHULUAN}

Pengembangan makanan khas daerah memerlukan beragam upaya, mengingat banyaknya kendala yang ditemui seperti gaya hidup modern yang mengakomodir makanan serba instan dalam tampilan menarik dibandingkan dengan makanan tradisional, daya simpan makanan yang tidak lama, rumitnya pembuatan, dan sebagainya. Di sisi lain makanan khas daerah memiliki keunggulan yaitu memiliki nilai yang memberikan manfaat bagi konsumen. Sehingga pelanggan bersedia membayar/membeli produk kuliner dan keunikannya yang tidak bisa ditemukan di kota lain, sebagai makanan yang terkait erat dengan nilai historis kesultanan Banten.

Sebagai komoditas produk pangan lokal, ada beberapa kendala yang menjadikan mereka kurang cepat dalam mengkembangkan bisnisnya antara lain adalah: (1) karena sifat produk yang tidak tahan lama, (2) kemasan produk yang kurang baik, (3) jangkauan pemasaran yang terbatas dan keterbatasan kemampuan dalam memasarkan produk, serta yang terakhir (4) kemampuan manajemen bisnis yang kurang memadai. Sebagai makanan khas kota Serang, komodifikasi sate bandeng sebagai kuliner lokal kota Serang merupakan suatu keniscayaan untuk dikembangkan sebagai industri pendukung pariwisata kota Serang. Apabila dikelola dan dikembangkan dengan baik, industri kuliner ini berpotensi tinggi sebagai sektor andalan untuk meningkatkan pendapatan asli daerah (PAD) kota Serang.

Setidaknya ada tiga hal yang dapat dijadikan acuan untuk menjadikan kuliner kota serang dapat berkembang menjadi daerah tujuan invstasi dan industri strategis. Ke tiga hal tersebut yaitu; nilai bagi konsumen, diferensiasi, dapat diperluas. Sate bandeng sebagai salah satu kuliner unggulan kota Serang, karena memiliki nilai yang memberikan manfaat bagi konsumen. Nilai inilah yang dapat menjelaskan alasan pelanggan untuk bersedia membayar/membeli produk kuliner. Di samping keunikannya yang tidak bisa ditemukan di kota lain, beberapa keunikan yang dimiliki kuliner kota Serang adalah makanan yang terkait erat dengan nilai historis kesultanan Banten. Dua alasan diatas merupakan point penting untuk komodifikasi, sehingga dengan komodifikasi dapat diperluas kehadirannya ke daerah-daerah lain melalui upaya pemasaran dan perdagangan lintas wilayah.

Kuliner sate bandeng memiliki potensi untuk dikembangkan sebagai komoditas pasar. Kuliner ini awalnya hanya dapat dikemas dalam bentuk kemasan dus yang hanya bertahan selama 2-3 hari saja. Namun saat ini, sate bandeng dapat dikemas untuk jangka waktu yang lebih lama, yakni 10 bulan dengan kemasan foil melalui proses penggunaan mesin vacum. Dengan adanya metode pengemasan ini, sate bandeng memiliki potensi yang lebih luas sebagai komoditas pasar sebagai oleh-oleh karena lebih tahan lama. Dengan kata lain, Kota Serang dapat mengembangkan kuliner yang satu ini karena memiliki potensi pasar, daya jual beli, dan komoditas pasar lebih luas sebagai oleh-oleh. Dengan adanya potensi ini, kuliner sate bandeng dapat dinikmati tidak hanya di tempat, tetapi dapat dibawa pengunjung sebagai oleh-oleh atau buah tangan.

Beberapa kendala yang menjadikan mereka kurang cepat dalam mengembangkan bisnisnya antara lain adalah: (1) karena sifat produk yang tidak tahan lama, (2) kemasan produk yang kurang baik, (3) jangkauan pemasaran yang terbatas dan keterbatasan 
kemampuan dalam memasarkan produk, serta terakhir (4) kemampuan manajemen bisnis yang kurang memadai.

Untuk mengatasi masalah-masalah IKM sate bandeng seperti yang telah diuraikan dalam bab sebelumnya, maka dibuatlah solusi untuk menyelesaikan permsalahan tersebut. Sebelum dipasarkan, para pelaku UKM sate bandeng akan diberikan pengetahuan dan pelatihan mengenai branding. Pengetahuan dan pendidikan mulai dari kemasan produk, sampai pada cara memasarkan produk, baik yang konvensional maupun yang online.

Sesuai dengan perkembangan ilmu komunikasi pemasaran, saat ini media sosial, karena karakteristiknya, mempunyai kemampuan untuk mem-branding. Media baru ini digunakan sebagai alat komunikasi pemasaran. Media sosial mampu memberikan solusi bagi permasalahan tingginya biaya pemasaran seperti promosi dan berbagai media komunikasi pemasaran pada umumnya. Fakta bahwa 5 sampai 10 tahun ke depan generasi $\mathrm{Y}$ dan $\mathrm{Z}$ akan menjadi pelaku utama perekonomian. Minat dan ketergantungan mereka terhadap internet, teknologi telekomunikasi semakin mereka embedded dengan smartphone.

Budaya belanja dan bisnis online menjadi lebih dominan. Dalam kaitan pemberdayaan IKM sate bandeng di kota Serang, maka dianggap urgent untuk memberikan pelatihan dan pendampingan pemasaran sate bandeng, baik dengan metode integrated marketing yang konvensional maupun pemasaran dengan memanfaatkan kemajuan teknologi telekomunikasi. Dalam era global saat ini kemampuan internet marketing menjadi suatu hal yang mutlak diperlukan. Terakhir, untuk menjadikan IKM dan UKM sate bandeng mampu bertahan dan bersaing, diberikan pelatihan mengenai manajemen bisnis. Anggota tim pada tahun ke tiga akan mengalami pergantian, mengingat kompetensi yang dibutuhkan pada tahap ini, lebih pada skill pengelolaan bisnis termasuk didalamnya pengelolaan keuangan.

Untuk mendukung realisasi pembinaan usaha ekonomi produktif kepada pengusaha kecil sate bandeng, tim pengusul program melakukan Serangkaian tahapan dalam melaksanakan solusi dari permasalahan mitra sebagai berikut :

a. Melakukan pendataan dalam rangka inventarisasi berbagai permasalahan yang lebih detail mengenai need dan want para mitra program.

b. Melakukan pendekatan dan koordinasi pengusaha kecil sate bandeng.

c. Menyusun materi pelatihan berdasarkan kebutuhan mitra program dengan mengacu pada tujuan dan target luaran program.

d. Menyelenggarakan program pelatihan

e. Melakukan evaluasi pelaksanaan program pelatihan

f. Melakukan improvement berdasarkan hasil temuan dan evaluasi program

g. Menyusun rencana pendampingan terhadap mitra program

h. Menyelenggarakan kegiatan pendampingan

i. Melakukan evaluasi dan monitoring terhadap mitra program

j. Melakukan improvement berdasaarkan hasil temuan dan evaluasi kegiatan pendampingan

k. Menyusun laporan pelaksanaan program pengabdian pada masyarakat. 


\section{METODE PELAKSANAAN}

Tahapan ini disusun untuk memudahkan dalam pelaksanaan kegiatan sejak perencanaan sampai dengan penyusunan laporan kegiatan pengabdian kepada masyarakat. Untuk melaksanakan kegiatan pengabdian pada masyarakat, tim pelaksana kegiatan akan melakukan Serangkaian kegiatan sebagai berikut:

\section{Rencana Kegiatan}

a. Pemetaan mitra permodalan

b. Pelatihan pengemasan

c. Pelatihan pemasaran online

d. Pendampingan pemasaran produk baik online (blog dan website gratis) dan offline (ke hotel dan rumah makan)

e. Pendampingan ke pameran-pameran dan toko-toko central oleh-oleh Banten

f. Membuat Model permodalan, pengemasan, dan standard operating procedure.

\section{Metode Pendekatan yang Ditawarkan Untuk Menyelesaikan Persoalan Mitra}

Pengabdian kepada masyarakat ini memiliki fokus memberikan wawasan wirausaha kepada pengusaha kecil sate bandeng. Metode yang digunakan dalam kegiatan ini adalah sebagai berikut:

a. Metode ceramah

Metode ceramah dimaksudkan sebagai metode penyampaian materi, di mana pemateri menyampaikan informasi seluas-luasnya tentang peluang wirausaha di bidang pembuatan sate bandeng yang awet tidak mudah basi, selanjutnya audiens diharapkan dapat mendengarkan dan menyimak dengan baik. Metode ini dilakukan untuk menggugah kesadaran dan semangat pengusaha kecil dalam menumbuhkan rasa ingin belajar cara mengolah ikan bandeng untuk menjadi sate bandeng yang gurih dan tidak mudah basi yang nantinya dapat membantu meningkatkan pendapatan keluarga.

b. Metode Workshop

Metode ini dilakukan untuk memberikan pengetahuan pengusaha kecil sate bandeng tentang membuat sate bandeng dengan pelatihan cara menjaga kualitas dan penyuluhan tentang meningkatkan kuantitas dari sate bandeng tersebut.

Metode pendekatan yang ditawarkan untuk mendukung realisasi program pengabdian pada masyarakat :

1. Penyuluhan yang dilakukan secara terjadwal

2. Memberikan pelatihan untuk kemasan yang menarik.

3. Memberikan pelatihan pemasaran online

4. Memberikan pelatihan manajemen bisnis IKM

5. Melakukan kerjasama dengan koperasi/perusahaan yang dapat memberikan modal pada pembuat sate bandeng.

Adapun rangkaian kegiatan pengabdian pada masyarakat yang akan dilaksanakan dalam tiga tahap tersebut, secara garis besar meliputi aktivitas-aktivitas di bawah ini.

1. Pendampingan pelatihan pengemasan.

2. Pendampingan pelatihan pemasaran online

3. Pendampingan pemasaran produk baik online (blog dan website gratis) dan offline (ke hotel dan rumah makan. 
4. Pendampingan ke pameran-pameran dan toko-toko central oleh-oleh Banten

5. Membuat Model permodalan, pengemasan, dan standard operating procedure Pemetaan mitra permodalan

6. Pendampingan perijinan ke Dinas - dinas terkait dan BPOM

\section{Partisipasi Mitra}

Kegiatan pengabdian pada masyarakat memerlukan peran aktif mitra. Oleh karena itu, mitra program diharapkan patisipasinya dalam rangkaian program selama tiga tahun. Partisipasi mitra meliputi :

a. Menyediakan produk sate bandeng

b. Mengikuti pelatihan pengepakkan/pengemasan yang baik dan menarik.

c. Mengikuti pelatihan pemasaran online.

d. Mengikuti pelatihan dan manajemen bisnis UKM

e. Mengurus perijinan dari dinas dinas terkait dan BPOM

f. Mengaplikasikan pengetahuan dan skill yang telah diberikan oleh para instruktur serta,

g. Mendiseminasikan ilmunya kepada kelompok produsen sate bandeng

\section{Evaluasi Pelaksanaan Program Dan Keberlanjutan Program Di Lapangan}

Sesuai dengan visi UNTIRTA bahawa program kemandirian pangan haruslah menjadi suatu program unggulan yang sustainable. Oleh karena itu, dalam pelaksanaannya, program ini akan dilakukan evaluasi secara periodik. Evaluasi dilakukan dengan tujuan untuk mengidentifikasi dan menginventarisasi permasalahan, serta kendala yang timbul selama proses berlangsungnya kegiatan. Hasil identifikasi dan inventarisasi masalah akan dijadikan sebagai bahan evaluasi untuk selanjutnya disusun rencana tindak lanjut sebagai solusi dari permasalahan dan hambatan yang muncul. Mekanisme demikian diharapakan menjadi pola perbaikan yang berkelanjutan (continual improvement) dalam kegiatan pengabdian pada masyarakat ini.

\section{HASIL KEGIATAN}

Pengusaha pengolah ikan khususnya sate bandeng sebagian besar belum mengunakan teknologi dalam pengelolaan sate bandeng, sebagian besar dari mereka masih sangat tergantung pada alat tradisional dan mengemas atau membungkus produk dengan daun pisang. Selain itu, kemasan yang ditampilkan dianggap kurang menarik. Pemasaran yang masih terbatas. Dalam proses pendampingan dan pembinaan usaha yang dilakukan oleh pemerintah, sampai saat ini belum optimal dan parsial tidak masif. Akibatnya tidak semua pengusaha pengolah ikan mendapatkan pembinaan dan berbagai fasilitas usaha yang dapat membantu mengembangkan usaha mereka, baik dalam bentuk permodalan, alat, dan pengembangan kualitas produk. Selain itu, belum terbentuk organisasi yang mampu menyatukan pengrajin sate bandeng secara menyeluruh. Kondisi ini membuat beberapa pengusaha sate bandeng mengalami kesulitan melakukan pengembangan usaha.

Permasalahan prioritas yang harus segera ditangani meliputi Permodalan, pengepakan (kemasan) dan pemasaran sate bandeng khususnya pengrajin sate bandeng usaha rumahan, serta manajemen bisnis IKM. Di samping itu, temuan di lapangan yang 
bersifat spesifik, konkrit serta benar-benar merupakan permasalahan mitra yaitu:

a. Proses produksi yang belum terstandarisasi, sehingga berpengaruh terhadap kualitas produk sate bandeng.

b. Pengepakan yang kurang menarik yakni hanya dengan daun pisang. Tidak mempunyai dana untuk menggunakan teknologi terkini karena masih mahal dan berbiaya tinggi.

c. Keterbatasan akses untuk mendapatkan fasilitas kemasan dengan teknologi yang memadai yang dimiliki dinas perindustrian kota Serang. Dalam pemasaran sate bandeng belum dapat dipasarkan sampai ke daerah-daerah lain, ke hotel-hotel, ke restaurant-restaurant, bahkan ke pasar-pasar modern. Serta belum mempunyai pengetahuan dan skill mengelola IKM secara profesional, sehingga penting untuk diberikan wawasan mengenai manajemen bisnis IKM.

Data di atas menunjukkan bahwa usaha sate bandeng sebagai icon produk kota Serang, perlu ditangani secara serius dan berkesinambungan. Selain pemerintah terkait yang memiliki program pengembangan usaha pengrajin sate bandeng, juga seluruh stakeholder yang terlibat di dalamnya bersinergi bersama dalam upaya pengembangan usaha, agar mereka tetap stabil menjaga kuantitas dan kualitas produk. Pembinaan dan pendampingan dari seluruh stakeholder juga menjadi sangat perlu, baik dari peningkatan kualitas produk maupun teknologi, perlu menjadi perhatian dalam proses pengembangan usaha. Bantuan modal dan peluang perluasan pasar menjadi faktor pendukung bagi kemajuan para pengrajin sate bandeng dalam menjalankan usahanya.

Berbagai pelatihan yang telah dilaksanakan selama ini mendapat antusias dari para pengrajin, hal ini tentu saja menjadi peluang besar mereka untuk maju, karena itikad baik dan semangat untuk memperbaiki kualitas produk dan usaha, serta manajemen pemasaran yang sudah dibangun selama ini. Sampai hari tidak sedikit lembaga yang ikut memberikan kontribusi bagi pengembangan usaha sate bandeng, baik dalam bentuk pelatihan, pameran, pengiriman delegasi, dan sebagainya sebagai upaya pencerahan dan meningkatkan wawasan bagi para pengusaha.

\section{KESIMPULAN}

Kemandirian usaha yang ingin dicapai perlu tindakan sistematis dan berkelanjutan dalam melakukan pendampingan, antara lain: (1). Dalam pemenuhan bantuan modal, pemerintah daerah bersinergi dengan instansi swasta maupun lembaga finansial lainnya, yang berpotensi melakukan pengembangan usaha kecil menengah melalui programprogram corporate social responsibility yang strategis. (2). Peningkatan kualitas dan kuantitas produk sate bandeng yang tetap terjaga, selain dapat dilakukan melalui berbagai pelatihan dan pendampingan, juga publikasi yang cukup untuk membantu perluasan pasar. Promosi seefisien mungkin, dengan biaya promosi yang tidak mahal namun mampu menyentuh pasar dengan jumlah yang tak terhingga banyaknya. Era sekarang cara ini sudah menjadi model komunikasi pemasaran yang banyak digunakan penguasaha, murah dan menguntungkan. Oleh karena itu, metode komunikasi pemasaran digital atau online perlu menjadi pendekatan yang dapat diaplikasikan oleh para pengusaha, dengan catatan tetap menjamin kualitas dan kuantitas produk, agar konsumen tidak kecewa. (3). Kemasan produk sebagai salah satu kesan awal yang harus diciptakan kepada pihak konsumen, sehingga bagaimana produk sate bandeng itu memiliki positioning product yang dapat diperhitungkan di pasaran, menjadi prioritas untuk terus 
dijaga dan ditingkatkan melalui berbagai pendekatan komunikasi pemasaran yang dapat membantu memberikan pengembangan model kemasan yang dapat memenuhi kebutuhan khalayak.

Semangat usaha yang harus selalu dibangun para pengrajin sate bandeng, untuk saling bahu membahu take give dalam mengembangkan produk, menjadi perlu. Suasana kondusif untuk saling memberikan dukungan di antara pengelola sate bandeng adalah kunci keberhasilan bagi keberlanjutan usaha. Oleh karena itu, Dinas terkait hendaknya terus memupuk semangat solidaritas dan kebersamaan untuk maju bersama dalam mengembangkan usaha sate bandeng sebagai icon kuliner Kota Serang/Banten

\section{DAFTAR PUSTAKA}

Aaker David \& Biel: 1993. Brand Equity \& Advertising: Advertising's Role in Building Strong Brands. USA.

Austin, M. S., \&Graiko, S. Digital and Social Media in the Purchase-Decision Process: A Special Report from the Advertising Research Foundation. Journal of Advertising Research, 52(4), 479. doi: 10.2501/jar-52-4-479-489. (2013).

Brandt, D. R. Website vs. Traditional Survey Ratings Do They Tell The Same Story?.Journal of Marketing Research, 24(3), 9-13. 2016. 678513 (2016).

Brannan, Tom. 1998. A Practical Guide to Integrated Marketing Communications Komunikasi Pemasaran Terpadu. PT. Gramedia Pustaka Utama - Jakarta.

Bruhn, Manfrendet all. Are social media replacing traditional media in terms of brand equity creation?.Journal of the Management Research Review.Vol. 35.No. 9.Tahun 2014

Burnett, John \& Sandra Mariaty. 1998. Introduction to Marketing Communications, an integrated Approach. London, Prince Hall International Inc.

Consalvo, Mia \& Charles, 2011. Ess.The Handbook of Internet Studies. Wiley-Blackwell Publishing.

Dillman, D. A. 2000. Mail and Internal surveys: The tailored design method. New York, NY. John Wiky Company.

Goldberg, Fishbein \& Middlestadt: 2007. Social Marketing: Theoretical and Practical Perspectives.

Hansel, Kyle \&Deis, Michele H. Using edia to Increase Advertising And Improve Marketing. Journal of Entrepreunerical Executive. Volume 15 tahun 2015.

Ivanauskas, Giedrius. 2009. The Evaluation of Social Media Effect on Marketing Communications: The UK Consumers Perspective. MA International Business and Marketing.

Ketter, Eran \& Eli, Avraham. The Social Revolution of Place Marketing; The Growing power of Users in Social Media Campaigns. Journal of Branding and Public Diplomacy.Vol. 8. 4. 285-294. (2012) 
Khang, Hyoungkoo. et all. Social Media Research in Advertising, Communication, Marketing, and Public Relations, 1997-2010.Journalism \& Mass Communication Quarterly. 2012

Kietzmann, J. H., Silvestre, B. S., McCarthy, I. P., \& Pitt, L. F. Unpacking the social media phenomenon: towards a research agenda. Journal of Public Affairs, 12(2), 109-119. doi: 10.1002/pa.1412 Labs| Global Pulse. (2012).

Kotler, Philip. 2002. Manajemen Pemasaran Edisi Milemium, PT. Prenhallindo, Jakarta.

Kunz, Michele B., et all. Fans, Friends, and Followers; Social Media in The Retailers' Marketing Mix. Journal of Aapplied Business and Economics.Vol. 12(3) 2014.

Lopez, Manuela \& Sicilia, Maria.How WOM Maarketing Contributes to New Product Adoption. European Journal of Marketing .Vol 47.Tahun 2013.

Lorenzo-Romero, C., \& Alarcón-del -Amo, M.-d. C. Segmentation of Users of Social Networking Websites. Social Behavior and Personality: an international journal, 40(3), 401-414. doi: 10.2224/sbp.2012.40.3.401 (2012).

Ludwig, S., de Ruyter, K., Friedman, M., Brüggen, E. C., Wetzels, M., \&Pfann, G. More Than Words: The Influence of Affective Content and Linguistic Style Matches in Online Reviews on Conversion Rates. Journal of Marketing, 77(1), 87103. (2014).

Metha, minu\&Anad. Richa.Social Media and Micro Entrepreuners; Lifestyle Marketing.Journal of Entreprunership and Management. Volume1 Issue 3 Oktober 2014

Moghavvemi, sedigheh, et all. The entrepreuner's perception on information technology innovation adoption; an empirical analysis of the role of precipating events on usage behavior. Journal of Marketing Communication Research, 24(3), 9-13. 2015.

Naseri, Mohammad Bakher\& Eliot, Greg. Role of demographics, social connectedness and prior internet experience in adoption of online shopping; applications for direct marketing.Journal of Targeting Management and Analysis for Marketing. Vol. 19, 2, 69-64 (2015)

Nekmat, E. Message Expression Effects in Online Social Communication. Journal of Broadcasting \& Electronic Media, 56(2), 203-224. doi: 10.1080/08838151.2015.

Peter \& Olson, 2000. Consumer Behavior perilaku konsumen dan strategi komunikasi pemasaran. Erlangga Jakarta

Rangkuti, Freddy. 2007. Riset Pemasaran. - Cet. 1. - PT. Gramedia Pustaka Utama. Jakarta 
Romaniuk, JAre You Ready for the Next Big Thing? New Media Is Dead! Long Live New Media! Journal of Advertising Research, 52(4), 397. doi: 10.2501/jar-52-4-397-399 . (2015).

Roulhudana, Fajar \& Hoesin, Hanif. 2014. Study Pengembangan SDM Wirausaha Bidang KOMINFO. Kajian eksplorasi pada wirausaha web \& hosting/datacenter, konten kreatif digital dan portal toko online. LaporanPenelitian DEPKOMINFO.

Roulhudana, Fajar. 2012. Model Komunikasi Bisnis E-Commerce UMKM Dalam Rangka Membangun Kepercayaan Konsumen (Trust) di Provinsi Sulawesi Selatan. Laporan Penelitian DEPKOMINFO.

Ryan, Damian. 2009. Understanding digital marketing : marketing strategies for engaging the digital generation. Kogan Page Limited London UK,Philadelphia USA.

Schultz, Don E, Tannenbaum, Stanley I and Lauterborn, Robert F. 2003. Integrated Marketing Communications. Illinois USA.

Shimp, Terence A. University of South Carolina. 2003. Promotion Management \& Marketing Communication. The Dryden Press.

Slyke, Craig Van,.Et all. Perceived mass and the adoption of a communication technology.European Journal of Information Systems. Vol. 16 July 2016.

Stieglitz, S., \& Dang-Xuan, L. Emotions and Information Diffusion in Social Media-Sentiment of Microblogs and Sharing Behavior.Journal of Management Information Systems, 29(4), 217-248. doi: 10.2753/mis0742-1222290408 (2015).

Sutisna. 2001. Perilaku Konsumen dan Komunikasi Pemasaran, Remaja Rosdakarya,

Tariq, Mohammad \& Wahid, Fazal.Assesing Effectiveness Of Social Media And Traditional Marketing Approaches In Terms Of Cost And Target Segment Coverage. Journal Of Institute Of Interdisciplinary Business Research. 2015.

Trout, Jack and Rivkin, 2007. Steve. The New Positioning. McGrow-Hill, Inc. Singapore.

Trurlow, Crispin., et all. 2004. Computer Mediated Communication; Social Interaction And The Internet. Sage Publication . California.

Yadin, Daniel L. 2009. Creating Effective Marketing Communications - Menciptakan Komunikasi Pemasaran Yang Efektif-. PT. Gramedia Pustaka Utama - Jakarta.

http://bisniskeuangan.kompas.com/read/2011/12/21/17014516/Indonesia.Capai.Puncak.B onus.Demografi.2017.2019 Twitonomy. (2017).

http://ekonomi.kompasiana.com/bisnis/2015/08/31/siapkah-kita-menghadapimasyarakat-ekonomi-asean-2015-684586.html 
http://inet.detik.com/read/2016/06/24/092646/2281884/398/3-manfaat-dahsyat-sosialmedia-bagi-e-commerce Chatoer. 2016.

http://jalantikus.com/tips/detail/1246/Infographic : Brand Terbesar di Media Sosial di Asia Tenggara pada tahun 2015-Jalantikus.com. (2015).

http://news.detik.com/read/2014/10/09/113752/2714005/10/siapkah-indonesiamenghadapi-pasar-bebas-asean-tahun-depan

http://swa.co.id/business-strategy/sdm-indonesia-belum-siap-menghadapi-mea-2015

http://techno.okezone.com/read/2015/08/18/92/851383/5-tips-berbisnis-online-difacebook

http://www.bappenas.go.id/node/168/3636/bkpm--indonesia-negara-anggota-g20dengan-pertumbuhan-terpesat-kedua/ .2015. 